\title{
Histological and histometrical evidences for phenol immunotoxicity in mice
}

\author{
Ali Louei Monfared • Afsaneh Jaafari • \\ Mohammad Taghi Sheibani
}

Received: 19 September 2012 / Accepted: 31 October 2012 /Published online: 17 November 2012

(C) The Author(s) 2012. This article is published with open access at Springerlink.com

\begin{abstract}
Phenol is a common industrial and ubiquitous environmental chemical which is used to synthesize resins and plastics. Due to its anesthetic and disinfectant properties, phenol is also widely used in pharmaceutical products. Since there were no adequate data about phenol immunotoxicity, the purpose of the present study is to investigate its toxic effects on the histological structures of the lymphoid organs in the mice. A total of 80 mice were randomly distributed into one control group and three experimental groups. The control group received only distilled water, whereas experimental groups were orally administered phenol at the concentrations of 80,180 , and $320 \mathrm{mg} / \mathrm{kg} /$ day, respectively. After 28 consecutive days, tissue samples were taken and histological changes of the spleens, thymuses, adrenal glands, and lymph nodes were examined using optical microscopy. The results showed that in the phenol treated animals; splenic megakaryocyte counts increased, the diameter of the splenic follicles decreased, the thymocyte population in both cortex and medulla reduced, the thickness of the reticular layers of adrenal gland increased and lymphatic cells populations in the lymph node were reduced, significantly $(P<0.01)$. Also, remarkable histological
\end{abstract}

A. Louei Monfared

Department of Basic sciences, Faculty of Para-Veterinary

Medicine, University of Ilam, Ilam, Iran

A. Jaafari

Department of Basic sciences, Faculty of Veterinary Medicine,

Ferdowsi University of Mashad, Mashad, Iran

M. T. Sheibani

Department of Basic Sciences, Faculty of Veterinary Medicine,

University of Tehran, Tehran, Iran

A. Louei Monfared $(\triangle)$

Banjonjab St-Pajhoohesh St-Ilam University,

Ilam, Iran 69315-516

e-mail: alm722@gmail.com changes were noted in the various lymphatic organs of the treated mice. Overall, present findings give some histological evidences that selected qualitative and quantitative parameters of the lymphatic organs were significantly altered by phenol administration. In conclusion, the significant decreases of the immune cell populations together with histological alterations in the immunocompetent organs of the mice exposed to phenol indicate the immunosuppressive and immunotoxic properties of this chemical material.

Keywords Histology $\cdot$ Phenol $\cdot$ Immunotoxicity $\cdot$ Mice

\section{Introduction}

Phenol $\left(\mathrm{C}_{6} \mathrm{H}_{5} \mathrm{OH}\right)$, a monohydroxy derivative of benzene, is used to synthesize resins and plastics (Finkelstein et al. 2007). Also, large amounts of phenol produced in industry and from other natural sources cause this chemical to be an important environmental and occupational hazard (Bruce et al. 1987). Due to its anesthetic and disinfectant properties, phenol is also widely used in pharmaceutical products such as ointments, ear and nose drops, sprays, and antiseptic lotions (Finkelstein et al. 2007).

The detrimental health effects attributed to phenol toxicity in the humans or animals include renal toxicity (Tootian et al. 2012), hematotoxicity (Louei Monfared and Salati 2012; Baj et al. 1994), immunotoxicity (Hsieh et al. 1988; Baj-Zeman et al. 1990), and neurological disorders (Windus-Podehl et al. 1983).

Tootian et al. (2012) investigated the nephrotoxic properties of the phenol in the mice. The cytotoxicity of phenol was attributed to phenoxyl-type radical production from phenol and their ability to impair epithelial cell membrane integrity (Tootian et al. 2012).

Baj et al. (1994) reported that in the workers who had been exposed for 6 months to vapors of phenol, 
formaldehyde, and organic chlorohydrocarbons; the number of T-lymphocytes and NK cell cytotoxicity were significantly decreased and lymphocyte proliferation was diminished. Also, subjects with the highest levels of phenol in the urine had decreased T-helper lymphocyte numbers and increased numbers of eosinophils and monocytes. The authors concluded that the functions of both the immune and hematopoietic systems could be affected by chronic exposure to these toxic substances (Baj et al. 1994).

Hsieh et al. (1988) reported immunotoxic effects of oral benzene (a parent chemical of phenol) exposure in the mice. They demonstrated that the immunotoxicity is the result of benzene metabolites including phenol.

Although the understanding of the toxic actions of phenol on the lymphoid organs is very important for occupational and public health, however, to the best of our knowledge, there is not a comprehensive study on histological and histometrical changes of the lymphoid organs after phenol exposure. So, the purpose of the present study was to investigate the effects of this chemical material on histological structures of lymphoid organs in the mice.

\section{Materials and methods}

\section{Chemical}

Phenol $(\mathrm{C} 6 \mathrm{H} 5 \mathrm{OH})$ was obtained from Biochem Chemical Co. (Tehran, Iran) and dissolved in distillated water. Deionized distilled water was used as the phenol career. Solutions of this chemical material at concentrations of 80 , 180 , and $320 \mathrm{mg} / \mathrm{kg}$ were prepared to provide the appropriate doses for experiments.

Animal and experimental design

To do the experiments, a total of 80 male $\mathrm{Balb} / \mathrm{C}$ mice, 9 10 weeks old, were purchased from Razi Institute (Karaj, Iran). The animals were maintained in a controlled environment at a temperature of $23 \pm 1{ }^{\circ} \mathrm{C}$, natural $12: 12 \mathrm{~h}$ lightdark cycle, and had ad libitum access to drinking water and food. Animals were allowed to be acclimatized to the laboratory environment for at least 7 days before commencement of testing. The mice were randomly allotted into four equal groups $(n=20)$; in which mice were exposed to different doses of phenol. The experiment was carried out for 28 consecutive days and animals were randomly divided into one control group and three experimental groups, each comprising of 20 mice. The control group received only distilled water, whereas experimental groups were orally administered phenol at the concentrations of 80,180 , and $320 \mathrm{mg} / \mathrm{kg} /$ day, respectively. The concentrations were determined on the basis of a primary study. Also, the concentrations and stabilities of the chemical were confirmed. All experimental procedures were carried out in accordance with institutional guidelines for animal care and use at the University of Ilam.

Histological and histometrical assessment

At the end of the administration period; the animals were anesthetized with chloroform vapor, quickly brought out of the jar, and sacrificed. For tissue assessment; the specimens from spleens, thymuses, adrenal glands, and sub-iliac lymph nodes were immersion imprisoned overnight in $10 \%$ neutral buffered formalin to be fixed. Then the specimens were mounted to allow $5-\mu \mathrm{m}$ sections. Sections were stained via hematoxylin and eosin method and photographed directly using a stereo microscope in 400 high power fields with Microsoft system.

For exact description of the structural changes in the lymphatic tissues, a histometrical analyze was performed. For this purpose, splenic megakaryocytes in unit area of $\left(1.44 \times 10^{4} \mu \mathrm{m}^{2}\right.$ tissue area) were determined by counting in 10 randomly selected areas in subcapsular white pulp regions (Salbacak et al. 2001) using Image Tool ${ }^{\circledR} 3.0$ software (UTHSCSA, San Antonio, TX, USA). Also, in each animal from all of the groups 10 tissue sections $(7 \mu \mathrm{m})$ were taken at $21 \mu \mathrm{m}$ intervals, and splenic capsule thickness, and also splenic follicular diameter were recorded. Furthermore, thymic capsule thickness, thymic cortex diameter, as well as thymic medulla diameters were recorded. In addition, the thickness of the glomerular, fascicular, reticular, and medullary layers of adrenal glands has been determined. Finally, the thickness of the lymph node's capsule and the diameter of the lymph node's follicles were determined according to Salbacak et al. (2001).

Data analysis and statistics

All results were expressed as standard error of the mean. The analysis of variance was used to test the overall significance of differences among the means. Tukey-Kramer's multiple comparison test was applied for post hoc comparison. Computations were performed using Statistical Package for Social Scientist (SPSS 11.5). A probability level of less than $5 \%(P<0.05)$ was considered as significant.

\section{Results}

Spleen

In the phenol-treated animals, spleen was severely affected; so that the splenic megakaryocyte counts have significantly 
increased in the treatment group (Table 1) in comparison with control animals $(P<0.01)$ (Table 1$)$. In these animals, both histological (Fig. 1d) and morphometric (Table 1) results have demonstrated severe splenic lymphocyte depletion. Although, the thickness of the spleen's capsule was not affected by phenol administration (Table 1) but the diameter of the splenic follicles showed a significant decrease in the phenol-treated animals compared to those of the controls $(P<0.01$; Table 1). It was not found any outstanding differences in the histological results between three experimental groups.

\section{Thymus}

Thymus tissue of the control group had normal cellular population in its cortical and medullar compartments (Table 1) while phenol treated mice demonstrated a reduction of the thymocyte population in the both cortex and medulla (Fig. 2c, d). In the mice administered with phenol, the diameter of the thymic cortex were significantly lower than those of the controls $(P<0.01$; Table 1$)$ while decreasing of the diameter of thymic medulla in those animals was not significant statistically. Also, the thickness of the thymus's capsule was not affected by phenol administration (Table 1).

\section{Adrenal glands}

In the control group, the adrenal glands have displayed normal histology with a large cortical and medullar compartments. But adrenal glands structures in experimental animals have been affected and lymphoid cells in its cortex and especially in reticular layer show significant increasing $(P<0.01$; Fig. $3 \mathrm{~b}$, Table 1$)$. Though, the medullar thickness of the adrenal glands was not changed by phenol treatment.

\section{Lymph node}

Sub-iliac lymph nodes of the control mice had typical histological integrity which was include large lymphoid follicles in the cortical area as well as massive lymphatic sinuses in the medullary area. In the treated animals, the tissue integrity of the lymph node was changed and lymphatic cells populations were reduced $(P<0.05$; Table 1). Furthermore, in the lymph nodes belonging to the experimental animals, empty spaces were seen around the follicles (Fig. 4b). The diameter of the lymph node's follicles of phenol given animals was also lower than those of the controls $(P<0.01$; Table 1$)$. In addition, the thickness of the lymph node's capsule was not affected by phenol treatment (Table 1).

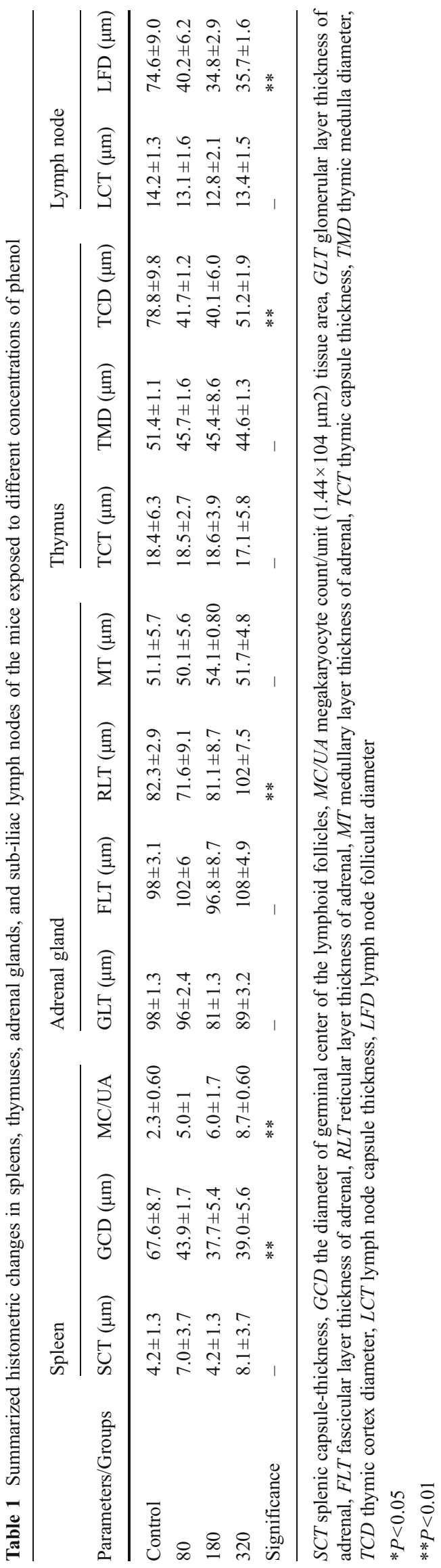


Fig. 1 Spleen transverse sections of the control $(\mathbf{a}, \mathbf{c})$ and $320 \mathrm{mg} / \mathrm{kg}$ phenol treated $(\mathbf{b}, \mathbf{d})$ animals. The $\mathbf{b}$ section shows abundant megakaryocytes (arrows) infiltration in the whole parenchyma of the spleen in the phenol-treated mice. The $\mathbf{d}$ section shows severe depletion (star area) of the different lymphoid cells in the whole parenchyma of the spleen in the phenol-treated mice (hematoxylin and eosin stain; a-d $\times 400$ )
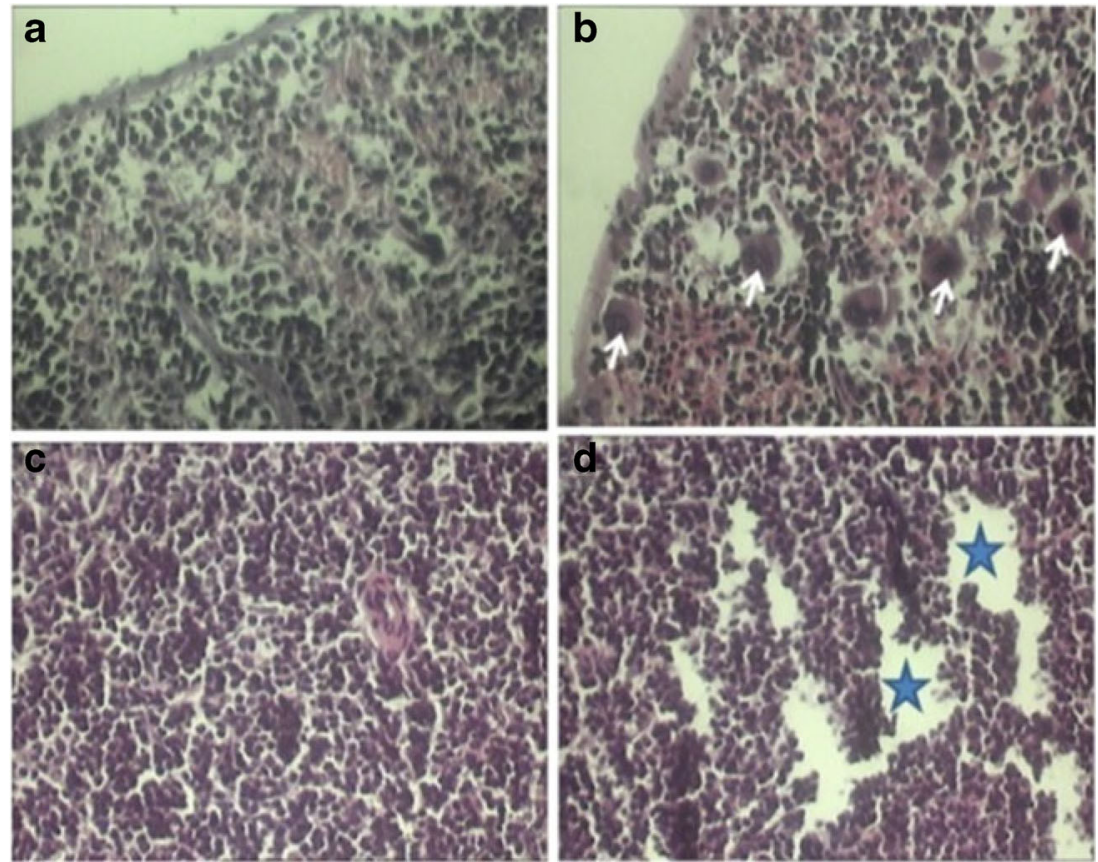

\section{Discussion}

Lymphoid tissues recently have received considerable attention as a target organ for the achieving the chemical materials toxicity (Hsieh et al. 1992). Present findings give some histological evidences that selected qualitative and quantitative parameters of the lymphatic organs were significantly altered by phenol administration.
In the present study, the cellularity of spleen was affected by the phenol administration. In other words, morphometric results have indicated that phenol caused profound suppression in the splenocytes population in the treated mice. Splenic immunosuppression may be attributing to the decreased different lymphatic cells numbers in the spleen as well as other immune organ. In line with these results, similarly, previous studies have demonstrated the immunological alterations on
Fig. 2 The transverse sections of the medulla of thymus in the control (a), the medulla of thymus in the $180 \mathrm{mg} / \mathrm{kg}$ phenol-treated (b) animals, the cortex of thymus in the control (c), and the cortex of thymus in the phenol-treated (d) animals. The figure shows that in the mice treated with phenol; severe depletion of the lymphoid cells from both cortex and medulla occurred (hematoxylin and eosin stain; a-d $\times 400$ )
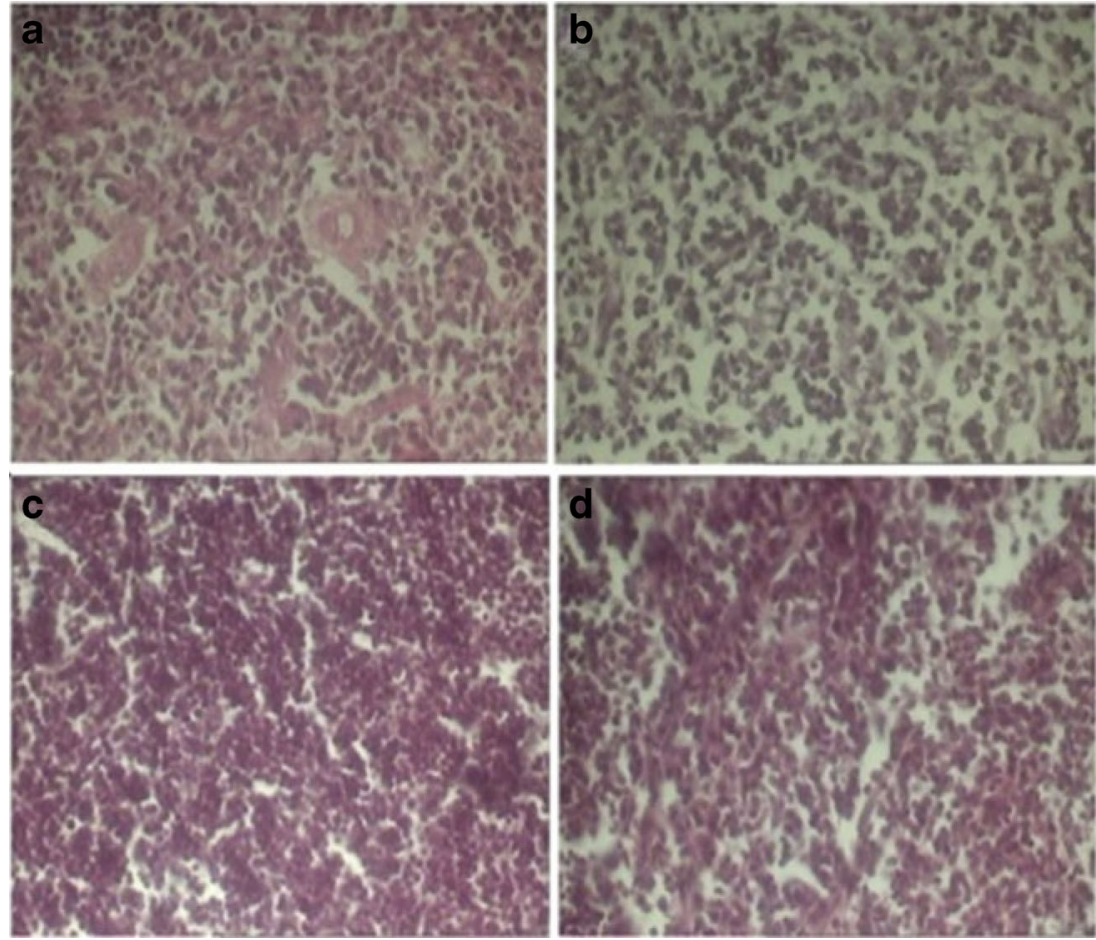
Fig. 3 The transverse sections of the reticular layer of adrenal cortex in the control (a) and $320 \mathrm{mg} / \mathrm{kg}$ phenol-treated (b) animals. The b section shows significant increase of the lymphoid cells in the reticular layer of the adrenal glands in the phenol-treated mice (hematoxylin and eosin stain; $\mathbf{a}, \mathbf{b} \times 400$ )
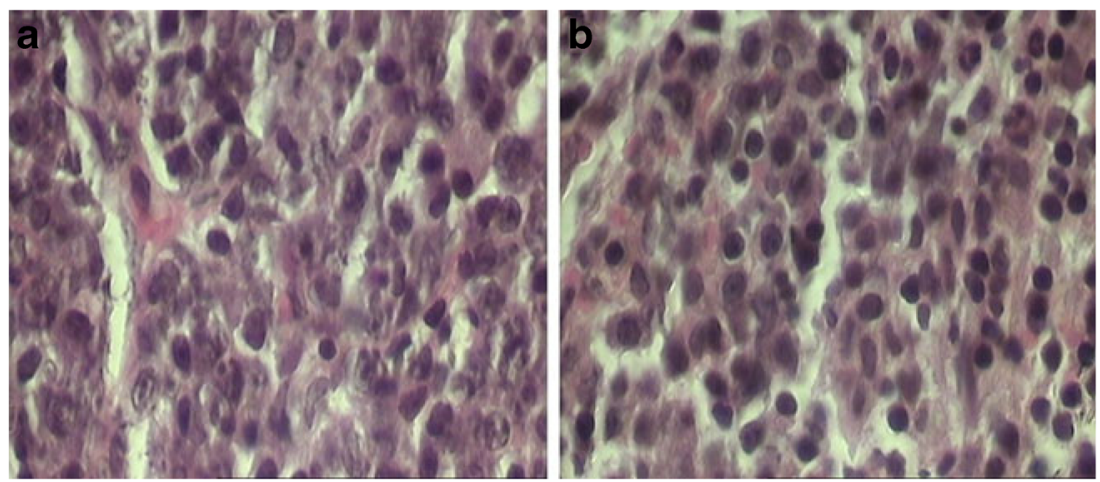

the splenic-forming cells and corresponding circulating antibody levels (Hsieh et al. 1992) in the CD-1 mice. In contrast, no spleen toxicity was observed in the study of Ryan et al. (2001) on the Sprague-Dawley rats. This dissimilarity may be associated with possible interspecies and inter strains differences between rats and mice for this endpoint. In addition, Hsieh et al. (1992) demonstrated that treatment with 19.5 and $95.2 \mathrm{mg}$ phenol/L in the drinking water inhibits the proliferative ability of splenic lymphocytes. Also, Berman et al. (1995) reported that an oral dose $224 \mathrm{mg} / \mathrm{kg}$ phenol caused spleen atrophy. The above mentioned findings are in accordance with our results.

In this study, phenol administration caused significant declines $(P<0.01)$ in the cellular population of the thymic cortex. In accordance with this result, Berman et al. (1995) reported that an oral dose $224 \mathrm{mg} / \mathrm{kg}$ phenol caused thymus atrophy or necrosis. Similarly, Moszcynski and Lisiewicr (1983) revealed a decrease in the number of T lymphocytes among workers exposed to benzene (a parent chemical of phenol) and several other solvents.

In the present study, overall thickness of the adrenal cortex has increased in the phenol treated animals, although statistical analysis have showed that adrenal reticular zone thickened significantly compared to those of control. Also, in the phenol given mice; the tissue integrity of the lymph node was changed, the diameter of the lymph node's follicles was reduced and empty spaces were formed around the follicles. This finding means adrenal hypertrophy as well as lymph node atrophy after phenol administration. Adrenal hypertrophy after phenol exposing may be due to hypothalamic-pituitary-adrenal axis activation resulting in high serum level of adrenal corticosteroids (Freier and Fuchs 1994). The atrophy of the lymph node is attributable to the decreased different lymphatic cells numbers in this organ resulting in suppress of the lymphocyte growth after phenol treatment. In this regards, Zeman et al. (1990) has been shown a decrease in the CD3 lymphocytes production together with decreased CD4/CD8 ratio and abnormal values of lymphocyte subpopulations in the workers whom exposed to phenol (Zeman et al. 1990).

In accordance with the results above, it has been demonstrated that phenol is main primary metabolite of benzene in the biological systems (Sawahata and Neal 1983) and benzene cause immunotoxic effects include lymphopenia and leucopenia in the human and animal studies (Avogbe et al. 2011; Wierda et al. 1981). Also, 1.4-dihydroxyphenol induced damages of chromosomes in human lymphocytes, which may led to leukemia progression (Zhang et al. 1998).

Although the mechanism(s) of phenol immunotoxicity are still unclear, but its ability to suppress the lymphocyte growth had been shown correlates with its oxidation capacity and with its concentration in the lymphoid organs and bone marrow (Pfeifer and Irons 1983). In addition, it has been suggested that phenol undergo hydroxylation reaction in the liver, alternatively with the consecutive production of catechol; which is converted to o-benzoquinoue. Subsequently, $o$-benzoquinoue derived from catechol is generally considered to be the toxic metabolites (Snyder
Fig. 4 The transverse sections of the sub-iliac lymph node in the control (a) and $180 \mathrm{mg} / \mathrm{kg}$ phenol-treated (b) animals. The b section shows significant decrease in the size of the follicles $(F)$ as well as empty spaces (arrows) around the follicles in the phenol treated mice (hematoxylin and eosin stain; a, b $\times 400$ )
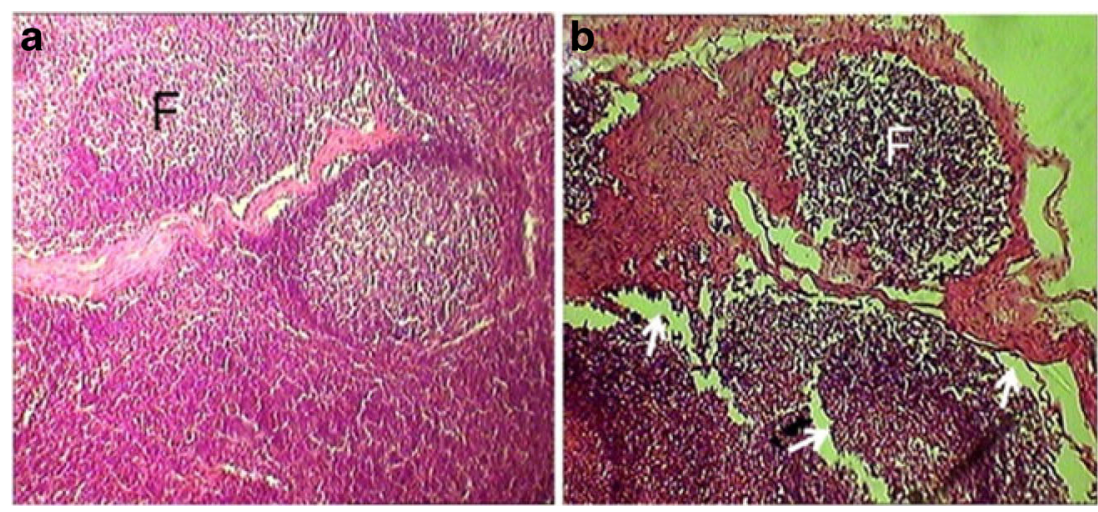
and Hedli 1996). This phenomenon is other assumable mechanism of action for phenol toxicity.

Beside liver's enzymes metabolism of phenol, the bone marrow contains several peroxidases and the most prevalent is myeloperoxidase (Subrahmanyam et al. 1991). On the other hand, it has been shown that phenol is transported to the bone marrow, where myeloproxidase is responsible for converting this chemical material to several biologically toxic compounds (Tsuruta et al. 1999). So, the myeloproxidase's ability to metabolize of phenol to toxic quinines in the bone marrow is other possible mechanism to phenol immunotoxicity.

In conclusion, the significant decreases of the immune cell populations in the immunocompetent organs of the mice exposed to phenol indicate the immunosuppressive and immunotoxic properties of this chemical material. Further studies will be needed to explore exact causative mechanism (s) and factors for phenol-induced immunological toxicity and especially in the search for suitable health surveillance methods.

Open Access This article is distributed under the terms of the Creative Commons Attribution License which permits any use, distribution, and reproduction in any medium, provided the original author(s) and the source are credited.

\section{References}

Avogbe PL, Ayi-Fanou L, Cachon B, Chabi N, Debende A, Dewaele D, Aissi F, Cazier F, Sanni A (2011) Hematological changes among Beninese motor-bike taxi drivers exposed to benzene by urban air pollution. Afr J Environ Sci Technol 5(7):464-472

Baj Z, Majewska E, Zeman K, Pokoca L, Dworniak D, Paradowski M, Tchórzewski H (1994) The effect of chronic exposure to formaldehyde, phenol and organic chlorohydrocarbons on peripheral blood cells and the immune system in humans. J Investig Allergol Clin Immunol 4(4):186-191

Berman EM, Schlicht M, Moser VC, MacPhail RC (1995) A multidisciplinary approach to toxicological screening: I. Systemic toxicity. J Toxicol Environ Health 45:127-143

Bruce RM, Santodonato J, Neal MW (1987) Summary review of the health effects associated with phenol. Toxicol Int Health 3:535-568

Finkelstein Y, Rezvani M, Garcia-Bournissen F, Nurmohamed L (2007) Inactive pharmaceutical ingredients: implications for pregnancy. Can J Clin Pharmacol 14(1):17-28

Freier DO, Fuchs BA (1994) A mechanism of action for morphineinduced immunosuppression: corticosterone mediates morphine- induced suppression of natural killer cell activity. J Pharmacol Exp Ther 270(3):1127-1133

Hsieh GC, Sharma RP, Parker RD (1988) Subclinical effect of groundwater contaminants. I. Alternation of humeral and cellular immunity by benzene in CD-I mice. Arch Environ Conta Toxicol $17: 151$

Hsieh GC, Sharma RP, Parker RD, Coulombe RA Jr (1992) Immunological and neurobiochemical alterations induced by repeated oral exposure of phenol in mice. Eur J Pharmacol 228(2-3):107-114

Louei Monfared A, Salati AP (2012) Hematological alterations induced by phenol exposure in Oncorhynchus mykiss. Comp Clin Pathol. doi:10.1007/s00580-012-1488-4

Moszcynski P, Lisiewicr J (1983) Effect of environmental contamination of the work place with benzene, toluene and xylene on human lymphocyte associated immunity. Med Lav 74:492-498

Pfeifer RW, Irons RD (1983) Alteration of lymphocyte function by quinines through sulfhydral-dependent disruption of microtubule assembly. Int J Immunopharmacol 5:463

Ryan BM, Selby RR, Gingell JM, Waechter JR, Butala JH, Dimond SS, Dunn BJ, House R, Morrissey R (2001) Two-generation reproduction study and immunotoxicity screen in rats dosed with phenol via the drinking water. Int J Toxicol 20:121-142

Salbacak A, Celik I, Karabulut AK, Ozkan Y, Uysal II, Cicekcibasi AE (2001) Effects of morphine on the rat lymphoid organs and adrenal glands: results of enzyme histochemical and histometric investigations. Rev Méd Vét 152(10):691-698

Sawahata T, Neal RA (1983) Biotransformation of phenol to hydroquinone and catechol by rat liver microsomes. Mol Pharmacol 23:453

Snyder R, Hedli CC (1996) An overview of benzene metabolism. Environ Health Perspect 104:1165-1171

Subrahmanyam VV, Kolachana P, Smith MT (1991) Metabolism of hydroquinone by human myeloperoxidase: mechanisms of stimulation by other phenolic compounds. Arch Biochem Biophys 286:76-84

Tootian Z, Louei Monfared A, Fazelipour S, Sheibani MT, Rouholla F, Sasani F, Molaemi E (2012) Biochemical and structural changes of the kidney in mice exposed to phenol. Turk J Med Sci 42 (4):695-703

Tsuruta T, Tani K, Hoshika A, Asano S (1999) Myeloperoxidase gene expression and regulation by myeloid cell growth factors in normal and leukemic cells. Leuk Lymphoma 32(3-4):257-267

Wierda D, Irons RD, Greenlee WF (1981) Immunotoxicity in C57BL/6 mice exposed to benzene and arochlo 1254. Top Appl Pharmacol 60:410

Windus-Podehl G, Lyftogt C, Zieve L, Brunner GJ (1983) Encephalopathic effect of phenol in rats. Lab Clin Med 101(4):586-592

Zeman K, Tchórzewski H, Baj Z, Nowak Z, Majewska E, Pokoca L, Kocur E, Kantorski J (1990) The effects of occupational exposure to hydrocarbons on some immune parameters of workers of the phenol division of a petrochemical plant. Pol J Occup Med 3 (4):399-407

Zhang L, Wangi Y, Shangn N, Smith MT (1998) Benzene metabolites induce the loss and long arm deletion of chromosomes 5 and 7 in human lymphocytes. Leuk Res 22:105 